\title{
Corpos subversivos: um olhar sobre o futebol na poesia de João Cabral
}

\author{
Subversive Bodies: A Look at Football in João Cabral's Poetry
}

\author{
Rodrigo Garcia Barbosa \\ Universidade Federal de Lavras, Lavras/Brasil \\ Doutor em Estudos Literários, UFMG \\ rodrigobarbosa@ufla.br
}

RESUMO: 0 presente ensaio busca identificar as dimensões artística, ideológica e afetiva através das quais o futebol é apreendido pela poesia de João Cabral de Melo Neto, com especial atenção para a dimensão ideológica e seus desdobramentos políticos, a partir da leitura de um poema sobre uma partida entre Brasil e Argentina.

PalavraS-chave: Futebol; Política; João Cabral de Melo Neto.

ABSTRACT: This essay seeks to identify the artistic, ideological and affective dimensions through which football is seized by João Cabral de Melo Neto's poetry, with special attention to the ideological dimension and its political developments, from the reading of a poem about a match between Brazil and Argentina.

KEYworDS: Football; Policy; João Cabral de Melo Neto. 


\section{PRIMEIRO TEMPO: O FUTEBol NA POESIA DE CABRAL}

Como a pintura, a literatura, a arquitetura e a dança, o futebol também se insere no rol de realizações artísticas e culturais sobre as quais se debruça a poesia de João Cabral de Melo Neto. Nesses casos, a atenção dos poemas quase sempre se concentra na forma como diferentes criadores realizam suas obras, ou como se dá o trabalho de concepção e execução do objeto que resulta de suas ações - quadro, livro, edifício, movimento -, abordagem reflexiva cujo teor crítico leva à identificação de uma poética, ${ }^{1}$ ou seja, de um modo de fazer próprio de cada artista, com suas implicações estéticas e éticas. Isso significa dizer que a relação entre a poesia cabralina e outras expressões de arte e de cultura se baseia principalmente no interesse pela forma como estas efetivamente se constituem, e normalmente surge a partir de uma relação de identificação com tais obras e com seus realizadores, em dimensões artísticas, ideológicas e afetivas.

Assim se dá, por exemplo, em versos como "Todos os gestos do fogo / que então possui dir-se-ia: / gestos das folhas do fogo, / de seu cabelo, sua língua", 2 que descrevem os movimentos corporais de uma bailadora andaluza, comparando-os com as formas móveis do fogo; ou em "Marianne Moore, em vez de lápis, / emprega quando escreve / instrumento cortante: / bisturi, simples canivete", ${ }^{3}$ versos que ilustram o estilo preciso e penetrante da poeta norte-americana, por meio da imagem do bisturi ou canivete transformado em instrumento de escrita; ou ainda em versos como "Fez-se enxertar réguas, esquadros / e outros utensílios / para obrigar a mão / a abandonar todo improviso",4 que figuram uma imaginária operação de implante que teria levado a mão direita do pintor holandês Piet Mondrian a pintar com a disciplina geométrica que caracteriza seus quadros. Tais exemplos demonstram a atenção que os poemas de Cabral dedicam ao modo de fazer da bailarina, da poeta e do pintor, ou seja, a suas respectivas poéticas, que

\footnotetext{
${ }^{1}$ Aqui a palavra poética designa um modo "específico de conceber e praticar a poesia", tal como definido por Roberto Acízelo de Souza (2019) em verbete sobre o conceito. Partindo dessa designação, ampliamos seu uso para um modo "específico de conceber e praticar" também outras formas de realização artística e cultural, como a poética de um pintor, de um arquiteto, de uma bailarina ou de um jogador de futebol.

${ }_{2}^{2}$ MELO NETO. Poesia completa e prosa, p. 195.

${ }^{3}$ MELO NETO. Poesia completa e prosa, p. 273.

${ }^{4}$ MELO NETO. Poesia completa e prosa, p. 274.
} 
implicam no reconhecimento de uma linguagem própria e consequentemente de uma obra única; atenção que se configura de maneira semelhante quando o artista observado é um jogador de futebol, como no poema intitulado "Ademir da Guia":
Ademir impõe com seu jogo
o ritmo do chumbo (e o peso)
da lesma, da câmara lenta,
do homem dentro do pesadelo.
Ritmo líquido se infiltrando
no adversário, grosso, de dentro,
impondo-lhe o que ele deseja,
mandando nele, apodrecendo-o.
Ritmo morno, de andar na areia,
de água doente de alagados,
entorpecendo e então atando
o mais irrequieto adversário. ${ }^{5}$

De maneira semelhante ao que acontece nos exemplos anteriormente apresentados, os versos acima descrevem a forma como o craque do Palmeiras e da seleção brasileira atuava nos anos 1960 e 1970, ressaltando seu ritmo lento, de "pesadelo", que se "infiltra", "entorpece" e "apodrece" o adversário, movimentos que se convertem em ação eficaz dentro do jogo e que são traduzidos (movimento e ação) em linguagem poética ${ }^{6}$ por Cabral, que identifica e destaca neles uma dimensão artística. Assim, "Ademir da Guia” realiza o mesmo que outros poemas do autor: apresenta criticamente o modo de fazer de um artista, reconhecendo nele uma linguagem própria e eficaz, constituinte de uma obra relevante e única, e que por isso justifica um interesse estético que busca em outras poéticas elementos para uma reflexão sobre o próprio modo de fazer artístico: uma crítica que se desdobra em autocrítica, confirmando a relação de identificação artística anteriormente mencionada.

Em análise do mesmo poema, Éverton Barbosa Correia reconhece uma "frouxa" (nas palavras do próprio pesquisador) relação afetiva entre o poeta e o

\footnotetext{
${ }^{5}$ MELO NETO. Poesia completa e prosa, p. 357.

${ }^{6}$ Já aqui a palavra "poética" designa os atributos próprios da "linguagem literária", e mais precisamente da "linguagem da poesia", cujas potencialidades rítmicas e imagéticas normalmente se afastam dos usos não-artísticos da linguagem.
} 
jogador de futebol, por conta de uma predileção de Cabral pelo Palmeiras, clube em que Ademir da Guia atuou por praticamente toda a carreira:

Para não excluir de todo qualquer possibilidade de ligação afetiva entre o poeta e o jogador do Palmeiras, vale a lembrança de que, devido ao tempo remoto de quando ainda era atleta juvenil do América Futebol Clube do Recife, João Cabral elegeu o América Futebol Clube do Rio de Janeiro como o de sua predileção, por ser homônimo do outro. Como não havia América em São Paulo, o clube eleito pelo poeta na antiga vila de Piratininga foi a Sociedade Esportiva Palmeiras, por ter o uniforme da mesma cor do América da sua cidade natal. ${ }^{7}$

Entretanto, concordamos com Correia que essa relação poeta-jogador é mais relevante quando observada do ponto de vista artístico do que do pessoal. Nesse caso, é interessante observar como essa poética de Ademir da Guia - uma poética do líquido, do podre, do torpe - não coincide com aquilo que comumente se associa à poética cabralina - uma poética do sólido, do árido, do lúcido -, apesar da obra de Cabral estar repleta de rios, mares, mangues, lama e outras imagens afins. Isso só reforça a lucidez e a abrangência da visão crítica da poesia cabralina, que se define por uma identificação artística que se dá não só por semelhanças, mas também por diferenças (nem sempre tão diferentes, como a extensa obra do poeta irá demonstrar), e que parece eleger a eficácia como o principal critério valorativo dos modos de fazer selecionados.

Por outro lado, as relações de identificação observadas na poesia de Cabral também se dão, de maneira relevante, em dimensão afetiva, senão em "Ademir da Guia", em outros poemas, inclusive quando o assunto é o futebol. É o que acontece no poema abaixo, dedicado a outro Ademir:

Você, como outros recifenses, nascido onde mangues e o frevo, soube mais que nenhum passar de um para o outro, sem tropeço.

Recifense e, assim, dividido entre dois climas diferentes, ambidestro do seco e do úmido como em geral os recifenses,

\footnotetext{
${ }^{7}$ CORREIA. Os Ademires de João Cabral de Melo Neto, p. 37.
} 
como você, ninguém passou de dentro de um para o outro ritmo nem soube emergir, punhal, do lento: secar-se dele, vivo, arisco. ${ }^{8}$

O poema "A Ademir Meneses" homenageia outro craque do futebol brasileiro, artilheiro do Sport Club do Recife, do Vasco da Gama e da seleção brasileira, nas décadas de 1940 e 1950. Apesar dos versos também ressaltarem a poética de Ademir Meneses - sua capacidade de passar "do mangue ao frevo", do "seco ao úmido", de um ritmo para outro, como um "punhal [...] vivo, arisco", evidenciando por meio da linguagem poética o modo de fazer do jogador, seu movimento eficaz e único, tal como acontece no poema dedicado a Ademir da Guia - dessa vez, no entanto, nos deparamos com um elemento diferente: se em "Ademir da Guia" a habilidade do jogador é simplesmente apresentada, sem menção a sua causa ou origem, em "A Ademir Meneses" a capacidade do craque de alternar os movimentos, de passar do "lento" para o "rápido", é atribuída a sua naturalidade recifense, à condição daqueles que nascem no Recife e que por isso se "dividem" desde o nascimento "entre dois climas diferentes", tornando-se em geral "ambidestro[s] do seco e do úmido", qualidade que Ademir Meneses desenvolveu como ninguém. A referência é importante porque ressalta a dimensão afetiva que se estabelece entre Cabral e Meneses: ambos pernambucanos, ambos recifenses.

Assim, a afetividade que no poema dedicado a Ademir da Guia praticamente não aparece, pelo predomínio da dimensão artística dentro da qual a abordagem se dá, fica evidente em "A Ademir Meneses", onde o interesse pelo modo de fazer do jogador, por sua linguagem ou poética, se junta ao elogio da cidade natal e de seus filhos ilustres, ainda que a poesia cabralina evite, como é sua característica, manifestações exaltadas de afeto. Com efeito, essa afeição por conterraneidade é comum na poesia de Cabral, que entre as personalidades pelas quais se interessa, incluindo suas obras e realizações, frequentemente menciona figuras de Recife e Pernambuco, fontes incontornáveis de sua poesia. É o caso, por exemplo, do poema "A Joaquim Cardozo", dedicado ao poeta, engenheiro e amigo recifense - "a cidade que não consegues / esquecer, / aflorada no mar: Recife, / arrecifes, marés,

\footnotetext{
${ }^{8}$ MELO NETO. Poesia completa e prosa, p. 365.
} 
maresias" -;9 ou do poema "O pernambucano Manuel Bandeira", dedicado ao primo e poeta consagrado - "Recifense criado no Rio, / não pôde lavar-se um resíduo" -;10 ou ainda de "A Pereira da Costa”, ao advogado, escritor e político, também recifense - "Quando no barco a linha da água / era baixa, quase naufrágio, / ele foi quem mais ajudou / o Pernambuco necessário". ${ }^{11}$

Definem-se assim as dimensões artística e afetiva que conformam as relações de identificação entre a poesia de Cabral e os objetos artísticos e culturais (e seus realizadores) pelos quais se interessa, incluindo nesse conjunto o futebol e seus jogadores. Mas, como mencionamos no início, uma dimensão ideológica também se insere nesse universo, dimensão que adquire muitas vezes um contorno político, direta ou indiretamente. É o que acontece, por exemplo, em poemas como "Fábula de Joan Brossa", cujos versos incluem, na descrição poética do modo de fazer do poeta catalão, a percepção de uma dura realidade humana, de pouca comida e muito trabalho, que no entanto não é repartida entre todos, mas destinada aos que não habitam os espaços mais privilegiados da cidade:

\author{
Mas porém como buscava \\ onde é o sol mais temporão, \\ pelo Clot, Hospitalet, \\ onde as vidas de artesão, \\ por bairros onde as semanas \\ sobram da vara do pão \\ e o horário é mais comprido \\ que fio de tecelão, \\ acabou vendo, Joan Brossa, \\ que os verbos do catalão \\ tinham coisas por detrás, \\ eram só palavras, não. ${ }^{12}$
}

Ou seja, o poema de Cabral percebe e evidencia na poética de Joan Brossa não só uma dimensão artística, mas também ideológica, revestida de contornos políticos que assumem uma posição de empatia pela condição daqueles que são desfavorecidos nas relações de força que configuram diferentes realidades econômicas e sociais.

\footnotetext{
${ }^{9}$ MELO NETO. Poesia completa e prosa, p. 56.

10 MELO NETO. Poesia completa e prosa, p. 358.

11 MELO NETO. Poesia completa e prosa, p. 361.

12 MELO NETO. Poesia completa e prosa, p. 128.
} 
De outra forma, mas ainda dentro dessa dimensão ideológica, o poema "Encontro com um poeta" traz à tona a voz de Miguel Hernández, ou sua linguagem, da qual se depreende seu modo de fazer, sua poética, ressaltando nela o combate do poeta espanhol ao franquismo que se configura a partir da Guerra Civil Espanhola (1936-1939) e que leva a sua prisão e morte em 1942, poesia de guerra em defesa do povo e contra o autoritarismo e a opressão:

\author{
Mas a voz que percebi \\ no vento da parameira \\ era de terra sofrida \\ e batida, terra de eira. \\ Não era a voz expurgada \\ de suas obras seletas: \\ era uma edição do vento, \\ que não vai às bibliotecas, \\ era uma edição incômoda, \\ a que se fecha a janela, \\ incômoda porque o vento \\ não censura mas libera. \\ A voz que então percebi \\ no vento da parameira \\ era aquela voz final \\ de Miguel, rouca de guerra \\ (talvez ainda mais aguda \\ no sotaque da poeira; \\ talvez mais dilacerada \\ quando o vento a interpreta). ${ }^{13}$
}

Aqui a dimensão ideológica que apontamos se reveste de um contorno político diretamente relacionado a um episódio que molda a história do século XX, com atores facilmente identificáveis, conformando assim um certo caráter de engajamento da poesia de Cabral diante dos conflitos políticos, sociais e econômicos que marcaram seu tempo, completando assim as dimensões que definem as relações que essa poesia estabelece com outras obras e outros artistas. E essa dimensão ideológica, com seus desdobramentos políticos, também está presente nos poemas cabralinos sobre o futebol, mesmo que indiretamente, como por exemplo no citado "Ademir da Guia", se considerarmos, como bem observa Éverton Barbosa Correia, que o jogador homenageado teve sua carreira marcada

${ }^{13}$ MELO NETO. Poesia completa e prosa, p. 132. 
por uma espécie de "exclusão" da seleção brasileira de futebol, apesar dos apelos do público e da crítica. Publicado no livro Museu de tudo, em 1975, o poema se insere no contexto da Ditadura Militar que se estabeleceu no Brasil de 1964 a 1985, período em que muitas vezes o futebol e a seleção brasileira foram palcos de ações e disputas políticas. Assim, não é exagero reconhecer a dimensão política de um poema que homenageia um jogador de futebol marcado pela "exclusão" de um símbolo nacional tomado frequentemente como símbolo do governo, principalmente no período mencionado; "exclusão" que atingiu seu ápice justamente um ano antes da publicação do poema, durante a Copa do Mundo de 1974, na Alemanha Ocidental, quando, apesar do clamor pela escalação de Ademir entre os titulares, o jogador só participou da última partida do torneio, na disputa do terceiro lugar contra a seleção da Polônia, sem ter tido chances, portanto, de participar dos jogos que valiam pela disputa do título mundial. Daí a dimensão política do poema, como observa Correia:

Como o poema não está datado, não dá para saber se o seu propósito comunicativo era o de fazer coro à reivindicação de escalar Ademir da Guia entre os titulares da seleção brasileira ou se, escrito após o fracasso de 1974, era uma crítica aberta aos militares e a seu representante no banco do time brasileiro, que era o ex-jogador e então técnico Mário Jorge Lobo Zagalo, resíduo das Copas anteriores, quando o Brasil tinha sido campeão. ${ }^{14}$

Configura-se assim, em síntese, o lugar do futebol na poesia de Cabral, a partir de uma relação de identificação do poeta que se configura nas dimensões artística, ideológica e afetiva. Neste ensaio, o ponto principal de interesse é o que se situa nas potenciais relações estabelecidas nos poemas cabralinos entre futebol e política, sem desconsiderar, contudo, as demais dimensões. Para tanto, faremos a seguir uma leitura mais atenta de outra obra do poeta, que tem o futebol como objeto de interesse.

\section{SEGUNDO TEMPO: UM CLÁSSICO SUL-AMERICANO}

Em 1987, João Cabral de Melo Neto publica a coletânea Crime na calle Relator, na qual inclui o poema a seguir:

\footnotetext{
${ }^{14}$ CORREIA. Os Ademires de João Cabral de Melo Neto, p. 41.
} 


\section{Brasil 4 x Argentina 0}

(Guayaquil 1981)

Quebraram a chave da gaiola

e os quadros-negros da escola.

Rebentaram enfim as grades

que os prendiam todas as tardes.

Nos fugitivos, é a surpresa,

vendo que tomaram-se as rédeas

(dos técnicos mudos, mas surpresos, brancos, no banco, com medo).

Estão presos os da outra gaiola, que não souberam abrir a porta:

ou não o puderam, contra o jogo dos que estavam de fora, soltos.

De certo também são capazes de idênticas libertinagens,

uma vez soltos, porém, como se liberar daquele tronco

em que os aprisionaram os táticos argentinos, também gramáticos?

E enquanto os fugitivos seguem com a soltura a sem lei que os regem,

nos bancos é uma a indignação:

dos que vão vencendo e dos que não:

"Voltamos ao futebol de ontem?

Voltou a ser um jogo dos onze?

Voltou a ser jogar de pião?

Chegou até cá a subversão?

Como é possível haver xadrez?

Sem gramática, bispos, reis? ${ }^{15}$

O poema faz referência a uma partida da fase final do Campeonato SulAmericano de Futebol Sub-20, disputado no Equador no início de 1981, período

${ }^{15}$ MELO NETO. Poesia completa e prosa, p. 584. 
em que Cabral ocupava o posto de embaixador no mesmo país, o que permite concluir que o poema parte de um testemunho do próprio poeta, conclusão reforçada pelo subtítulo que faz questão de registrar local e data. A princípio, o que chama a atenção do leitor é o título da obra, não apenas pela posição de destaque e o caráter orientador da leitura que os títulos ostentam, mas pela excepcionalidade daquilo que ele designa: uma goleada do Brasil sobre a Argentina, seu grande rival sul-americano, por quatro a zero, resultado geralmente incomum entre adversários igualmente tradicionais e fortes, que confere uma grande vitória e uma grande derrota aos envolvidos. Mas, iniciada a leitura dos versos que compõem o poema, a atenção se desvia do resultado e passa a acompanhar a causa desse acontecimento excepcional, ou aquilo que no modo de fazer dos jogadores brasileiros provocou a vitória extraordinária, com consequências dentro e fora do jogo.

Nas quatro primeiras estrofes, o poema apresenta o que parece ser a principal razão do triunfo brasileiro: a liberdade que, sem justificativa aparente, os jogadores brasileiros se concederam, rompendo as amarras táticas que prendiam seus movimentos em campo, em um gesto de insubordinação sintetizado pela imagem dos "fugitivos" que "tomaram-se as rédeas". A ação é surpreendente, tanto para os jogadores quanto para os técnicos, símbolos das grades que impediam o melhor jogo, o dinamismo eficaz que leva aos gols e à vitória, como os movimentos dos dois Ademires, da Guia e Meneses, apresentados acima. E a surpresa dos treinadores é tal que, ao contrário dos atletas, que se soltam, eles se prendem, em uma estrofe que é a imagem de seu assombro, se considerarmos não só a mudez e a palidez que os acomete, sintomas do susto e do medo pelos quais são tomados, mas também o lugar definido e limitado que ocupam - o banco, não só o espaço destinado àqueles que não jogam a bola, e que designa a imobilidade de quem passa o jogo assentado, mas também, a partir de uma leitura subversiva como a liberdade dos brasileiros em campo, o lugar seguro para onde "fogem" aqueles que sentem ameaçada sua posição, o banco e seus cofres, que guardam e protegem. Daí ser intrigante o verso "brancos, no banco, com medo", um quase retrato ou uma caricatura da tradicional parceria entre o poder econômico e as classes que preferem cidadãos subordinados e subservientes a suas regras historicamente definidas, principalmente em países como os da América Latina, onde "brancos 
com medo" se refugiam no poder do dinheiro quando se sentem ameaçados pelos "não-brancos". Ainda mais se lembrarmos o velado preconceito que, no Brasil, faz predominar os técnicos brancos e os jogadores negros e mestiços, como se o trabalho intelectual fosse destinado a uns e o trabalho corporal, de pernas, troncos e braços, fosse destinado a outros, projetando no futebol as hierarquias que estruturam a sociedade. Assim, os "brancos no banco" representam uma dupla condição, futebolística e social, baseada em pressupostos hierárquicos análogos. Mas a imagem do assombro dos técnicos que a estrofe produz ainda se completa com os parênteses que, como um muro, uma parede, um escudo, encerram e protegem os amedrontados treinadores, isolando-os dos subversivos jogadores, projetando na concretude gráfica da página a imagem mental construída a partir das palavras.

Assim, a insubordinação tática dos jogadores brasileiros assume a dimensão de uma insubordinação política, a partir dos sentidos que o poema insere no jogo, reconhecendo no futebol um campo do qual se depreendem aspectos importantes de diferentes contextos sociais, políticos e históricos. Isso fica ainda mais evidente nas cinco estrofes seguintes, que desviam a atenção do poema para os jogadores argentinos, que diferentemente dos brasileiros permanecem presos. Nesses versos, apesar da diferença entre a liberdade de uns e a sujeição de outros, o poema destaca a condição semelhante que, pelo menos até o início da partida, aproximava os atletas dos dois países: ambos presos às regras táticas, ambos "capazes de idênticas libertinagens". Tal proximidade reforça o caráter político do poema, se considerarmos o contexto em que ele foi escrito: a partir de uma partida de futebol disputada no ano de 1981, quando Brasil e Argentina ainda viviam sob o domínio das ditaduras militares que marcaram a história da América do Sul na segunda metade do século XX. Sob esse contexto, o poema de Cabral faz do jogo de futebol uma alegoria da opressão experimentada nesses países, em que um poder centralizador, do ditador como do técnico, busca submeter a uma vontade única e uniformizadora as diferentes vontades, dos cidadãos como dos jogadores, impondo uma ordem totalizadora e impessoal, que automatiza os comportamentos e movimentos, e da qual só resulta vitórias mesquinhas, e não a vitória excepcional que o poema testemunha. 
Esse aspecto alegórico, com implicações históricas e políticas, é reforçado por imagens como a do "tronco" em que estão presos os jogadores argentinos, imagem de forte simbolismo na história brasileira, por designar o local em que eram acorrentados os negros escravizados para serem castigados com chicotadas, e que remete à violência que historicamente atinge os oprimidos no Brasil, na Argentina e em outros países americanos: povos ameríndios e africanos escravizados pelo invasor europeu, homens e mulheres submetidos ao autoritarismo e à dominação física e cultural que se tornaram tradicionais nesses países. Com isso, a referida imagem entrelaça a condição dos jogadores dos dois times (e que transborda para os "jogadores" de todo o continente), entrelaçamento que se materializa na própria estrutura das estrofes que compõem o poema, constituídas por pares de versos que denotam tanto o antagonismo da disputa esportiva quanto a cumplicidade das condições históricas comuns.

Daí o caráter libertino do modo de fazer dos atletas brasileiros, seu repentino livrar-se de uma ordem que aliena a vontade do corpo próprio (do jogador) para a satisfação da vontade de um corpo alheio e distante (do técnico). Afinal, o modo de fazer dos jogadores de futebol se realiza com o corpo, como uma poética do corpo. Não por acaso, em outro poema de Cabral a bola de futebol é referida como "utensílio semivivo",16 que precisa ser utilizado com "malícia e astúcia de mão", como quem interage com uma "mulher", conferindo ao jogo uma dimensão de intimidade que reforça sua condição corpórea, confirmando aquilo que explica José Gil: "o esportista prolonga o espaço que rodeia a sua pele, tece com as barras, os tapetes, ou simplesmente com o solo que pisa relações de conivência tão íntimas como as que têm com o seu corpo". ${ }^{17}$ Tal intimidade não comporta a automatização dos movimentos de uma peça de xadrez, ou a indiferença dos gestos de uma marionete, mas exige uma tomada de posição, uma implicação do corpo que necessariamente constitui um éthos próprio, tal como ensina Roland Barthes ao abordar a escrita ${ }^{18}$ - o que reforça a relação e a identificação entre poeta e jogadores. E essa libertação dos corpos comumente afronta as táticas que pregam a submissão

\footnotetext{
${ }_{16}$ MELO NETO. Poesia completa e prosa, "O futebol brasileiro evocado da Europa", p. 381.

17 GIL. Movimento total, p. 47.

${ }^{18}$ BARTHES. Inéditos, I, p. 174-255.
} 
das individualidades diversas à totalidade unificadora, seja nos campos de futebol ou fora deles: basta pensar em como governos totalitários historicamente atacam as manifestações artísticas e culturais que não se enquadram nos modelos que julgam "apropriados", assim como os comportamentos que não se reduzem ao que tais governos e seus apoiadores entendem como "normal"; mas basta também pensar na força subversiva de um gesto como o do centroavante Reinaldo, do Atlético e da seleção brasileira: braço direito erguido, punho cerrado, corpo estancado em monumento contra a ditadura militar em plena década de 1970; ou, também durante a ditadura, pensar no comportamento desviante de Paulo César "Caju", campeão do mundo com a seleção no México, irreverente e insubordinado aos padrões estabelecidos para o "bom" jogador, corpo em evidência nos modos, no comportamento, nos cabelos. ${ }^{19}$

Mas que fique claro, essas "libertinagens" não implicam em uma anarquia dos jogadores no campo de jogo: elas instituem uma nova ordem "sem lei", mas que "os regem", um reger-se mútuo, sem donos ou senhores, ordem de corpos livres e comunicantes, que constituem uma "intimidade" entre si, fazendo o time jogar um "verdadeiro" futebol brasileiro. Afinal, é justamente "O futebol brasileiro evocado da Europa" o título do poema de Cabral que alerta sobre a necessidade de tratar a bola com intimidade, malícia e astúcia, marcas da beleza e eficácia tradicionalmente associadas ao futebol brasileiro. Ou seja, a goleada de 4 a 0 sobre a Argentina representa, aos olhos do poema, uma retomada de um futebol que estava esquecido, como deixam claro os versos que compõem as cinco estrofes finais, que dando voz aos técnicos indignados perguntam: "Voltamos ao futebol de ontem?”, "Voltou a ser jogar de pião?", em uma referência à tradição desse futebol que, por sua vez, remete à irreverência e espontaneidade de jogo primordial, atemporal, que se joga com a inteligência lúdica do corpo.

Nessas estrofes finais também se confirma o caráter político do poema, que ao perguntar se “Chegou até cá a subversão?" transporta para dentro do futebol, e consequentemente da poesia, o jargão utilizado pelas autoridades para designar aqueles que se contrapunham à ditadura no Brasil, ou que se posicionavam a favor

19 Sobre Reinaldo, Paulo César e outros jogadores que de alguma forma confrontaram a Ditadura Militar no Brasil, conferir: COUTO, Da ditadura à ditadura. 
de um regime mais democrático e uma sociedade mais justa, tachados pejorativamente de "subversivos". Isso ainda é reforçado pela "indignação" geral dos técnicos, vencedores e vencidos, mais derrotados pela quebra da hierarquia até então prevalecente do que por uma possível derrota esportiva, sugerindo que a partida é apenas o pano de fundo para uma disputa muito maior, na qual aparentes adversários se revelam na verdade cúmplices. Nesse sentido, a última estrofe oferece mais uma daquelas imagens que transitam de um campo a outro, iluminando-se mutuamente, ao perguntar, pela voz dos mesmos técnicos indignados: “Como é possível haver xadrez? / Sem gramática, bispos, reis?”. Afinal, se ela revela a incapacidade de conceber uma ordem sem uma hierarquia que preveja subordinadores e subordinados, garantindo assim sua posição de comando, seu status privilegiado, ordem ilustrada pela "gramática" do jogo de xadrez, a imagem também sugere que sem essa hierarquia que amarra e aliena não é "possível haver xadrez" - ou seja, não é possível haver celas e prisões, tática predileta de governantes autoritários.

\section{ACRÉSCIMOS}

Ao longo do ensaio observamos como a poesia de João Cabral de Melo Neto, assim como faz com outras realizações artísticas e culturais, toma o futebol como objeto, partindo de um interesse que abarca as dimensões artística, ideológica e afetiva, buscando identificar no modo de fazer dos jogadores elementos constituintes de sua linguagem, que levam a reflexões ordem estética, política e pessoal. Apesar disso, nos concentramos mais em ressaltar o conteúdo político dos poemas escolhidos, sem deixar de reconhecer que as dimensões artística e afetiva também estão presentes em qualquer uma das obras citadas. Afinal, a tomada de posição que tais poemas representam advém do modo de fazer do poeta, que constitui um éthos próprio e resulta em uma linguagem única e eficaz, como um grande jogador que, com movimentos inconfundíveis, transporta para os gramados as marcas de sua história. 


\section{REFERÊNCIAS}

BARTHES, Roland. Inéditos, I: teoria. Trad. Ivone Castilho Benedetti. São Paulo: Martins Fontes, 2004a. (Coleção Roland Barthes).

CORREIA, Éverton Barbosa. Os Ademires de João Cabral de Melo Neto. Aletria: Revista de Estudos de Literatura, Programa de Pós-Graduação em Estudos Literários da UFMG, Belo Horizonte, v. 26, n. 3, p. 33-48, set.-dez. 2016.

COUTO, Euclides de. Da ditadura à ditadura: uma história política do futebol brasileiro (1930-1978). Niterói: Editora da UFF, 2014.

GIL, José. Movimento total: o corpo e a dança. Trad.: Miguel Serras Pereira. São Paulo: Iluminuras, 2004.

MELO NETO, João Cabral. Poesia completa e prosa. Organizador Antonio Carlos Secchin. 2 ed. Rio de Janeiro: Nova Aguilar, 2008.

SOUZA, Roberto Acízelo de. Poética. In: E-Dicionário de Termos Literários (de Carlos Ceia). Disponível em: https://edtl.fcsh.unl.pt/encyclopedia/poetica/. Acesso em: 13 dez. 2019. 